\title{
Corporative Trends in Urban Distribution of Goods in Mexico City
}

\author{
Juan Pablo Antún \\ Grupo de Investigaciones en Ingeniería de Transporte y Logística (GiiTRAL) \\ Instituto de Ingeniería, Universidad Nacional Autónoma de México (UNAM) \\ Apdo Postal 70-347, Ciudad Universitaria, México DF (04510), MEXICO \\ jantunc@iingen.unam.mx
}

Keywords: Logistics, supply chain, urban distribution of goods, urban freight

\begin{abstract}
The Logistics processes in urban-metropolitan distribution are constantly changing, both technological support and technical implementation in the processes themselves and in the management of these. It is necessary to monitor the substantive changes outlined in the metropolitan urban-physical distribution of goods, because they contribute to a better competitive position of companies in the market, and also to a better development of city life. It is a professional scientific and technical task that contributes, by its impact on "benchmarking", the improvement of engineering practices in the professional community of executives in logistics and supply chains. Based on three extensive field research (ANTÚN, JP; LOZANO, A; HERNÁNDEZ, R; ALARCÓN, R et al 2007; ANTÚN, JP; LOZANO, A; MAGALLANES, R; ALARCÓN, R; GRANADOS, F 2009, ANTUN JP ALARCON R; 2014) on Logistics Distribution of Goods in Mexico City, this article presents and discusses major corporate trends on a set of key logistics processes, and bring examples from Case Studies.
\end{abstract}

\section{INTRODUCTION}

The article reveals a set of eight corporate trends:

(1)Reduction of inventories through an integrated system by a single distribution center and a set of Load Centers for Ordering through satellites "cross-docking", to meet levels of customer service

(2)Development of innovative alternatives for order processing and customer service

(3)Order Processing batch and limitation of spray deliveries in "e-commerce"

(4)Development of processes and reverse logistics operations to meet requirements of standards and policies for recycling

(5)Introduction of innovations in information technology in logistics

(6)Innovation in Vehicle Technology

(7)Outsourcing of operations through logistics operators with dedicated fleets

(8)Preference for locating logistic supports at Logistic Centers

For each of the trends are presented their characteristics and importance for the competitive positioning of the companies discussed.

While companies are mentioned in the studies, only reference to innovation without detailing the logistics processes, to respect confidentiality agreements is made.

The logistics innovations are the key to the metropolitan competitiveness.

\section{CORPORATE TRENDS IN URBAN DISTRIBUTION OF GOODS}

\section{Trend 1:}

Reduction of inventories through an integrated system by a single distribution center 


\section{and a set of load centers for the fullfilment of orders through satellites "cross-docking", and to meet levels of customer service}

As inventories represent on average, for the different industrial activities, just over $30 \%$ of logistics costs, there is always an obsession to reduce them.

Mix diversification offered to the market and the demands of homogeneity in the level of service are the vectors most stocks soar in metropolitan urban distribution

Current strategies for the reduction of inventories are:

\section{(1) Expansion limitation of the SKU mix, through better management of product life cycle}

Better interaction between the areas of Marketing and Logistics in the company to manage the life cycle of the product and limit the expansion of the offered SKU mix.

In order i) to preserve the classic products rated $\mathrm{A}$, ii) to eliminate out of the mix products rated $\mathrm{B}$ - and with lower turnover, and iii) to control the timing of introduction, the sales triggering, and decline of new products.

Case 1

Coca Cola FEMSA are handled SKU "input output" considering promotional "packs" (christmas, football, etc)

\section{(2) Reduction of the number of distribution centers}

The split of the inventory with $\mathrm{C}_{0}$ units of a SKU in a single distribution center (DCs) that caters to service level s market $\mathrm{M}$ (ie: s 100 consumers in $\mathrm{M}$ are satisfied), n CEDIS with $\mathrm{C}_{1}, \mathrm{C}_{2}, \ldots \mathrm{C}_{\mathrm{n}} \mathrm{SKU}$ units considered, attending the same level of service $\mathrm{s}$ territorial segments $\mathrm{M}_{1}, \mathrm{M}_{2}, \ldots \mathrm{M}_{\mathrm{n}}$ market served assigned to each CEDIS implies that the total number of units considered SKU will be approximately proportional to the original number units in the situation of a single distribution center $\mathrm{C}_{0}$ multiplied by the square root of $\mathrm{n}$ splits the original inventory (ie, the current number of distribution centers).

Obviously the global trend more pronounced in metropolitan urban physical distribution is to close CEDIS to lower logistics costs and make "centralized" distribution

\section{Case 2}

UNILEVER recently consolidated the logistics operation of different business units acquired in recent years by association and merging, closing CEDIS in metropolitan distribution operation

\section{(3) Assessment and monitoring of the type of products that make up the "mix" based on} the level of rotation by territorial served market segments

As companies do not put on the market a single product but a basket or product mix, the cost of inventories also increased to the extent that this diversified mix expands depending on the level of adaptation that look to the needs of customers ("customization"). The level of rotation of each SKU is classified as high (A), middle (B) and low rotation (C, D); You can even more discriminated rotational level (eg $\mathrm{A}+, \mathrm{A}, \mathrm{A}-$-). This qualification must be monitored continuously. If market conditions and / or practices of the competition force open new distribution centers to avoid the explosion of logistics costs, current practices restrict inventory that partition only to products of higher turnover.

\section{Case 3}

The alliance AIRES DEL CAMPO, a prestigious distributor of certified organic products, with WalMart, considers mix segmentation by the location of SUPERAMA shops.

(4) Ranking of inventories based on the level of rotation of the items in the mix As stated in the previous paragraph leads to inventories on each distribution centers (DC) to ensure low costs and an adequate level of customer service: a DC is usually adopted as "central" where stocks are maintained to meet with level service s entire demand for the 
products $\mathrm{C}$ and $\mathrm{D}$, and inventory on the whole network of distribution centers only for items $\mathrm{A}$ and $\mathrm{B}$ is partitioned. Often the SKU rated B, are in stock if only have exposure to risk from competition.

\section{Case 4}

Coca Cola FEMSA segments the marketing mix in CEDIS by level of rotation of each SKU

(5) Management of security levels in inventories in local DC by backup in central DC A recent trend applies a more sophisticated strategy of differentiation of service levels s1, s2, ... $\mathrm{S}_{\mathrm{n}}$.. for each territorial market segment served by each distribution center (DCs) for the same level of rotation SKU, with a support for inventory ruptures assigned to $\mathrm{C}_{0}$ *

\section{Case 5}

Inventory management in warehouses of spare parts (auto parts) of distributors NISSAN is "protected" with a central inventory in Toluca (and a second backup in Los Angeles, USA for imported vehicles) and industrial parcel shipments by ESTAFETA

(6) Implementation of cross-docking satellites to guarantee a consistent level of service to peripheral regional territorial market segments

To Close DC could jeopardize the efficient consumer response (ECR), in particular i) territorially large metropolitan areas (such as the Metropolitan Area of Mexico), and ii) urban areas with an internal network spatial structure and complex road (as in historic centers). A strategy to mitigate these risks is the implementation of cross-docking satellites of a Distribution Centers, obviously with only inventory in transit to fill multiple orders in a day by a family of delivery routes (for example with a cross docking in city logistics micro platform in the Historic Center to integrate cargo units of electric vehicles for delivery to retailers) or to articulate hierarchical levels in a delivery route in the territory of the distant market (eg moving from a Distribution Centers the end of the day in a vehicle product articulated city logistics micro platform in a peripheral area of conflict which can force access to a large travel time if the operation was done during the morning, so that it is available at the beginning of the day and can "launch" early one or two local delivery routes).

\section{$\underline{\text { Case } 6}$}

Coca Cola FEMSA operates some Distribution Centers loading trucks in the afternoon sent to a peripheral parking, to start sharing early in the morning, then substantially reducing the trunk route (or "long") to concentrate on the routes "local "delivery.

\section{Trend 2:}

\section{Development of innovative alternatives for processing of orders and customer service}

The Order Processing is one of the four key logistics processes and is inherently associated with two others process: Inventory Management and Customer Service.

The order cycle, whose operations define the "lead time" (time between the moment when the customer places the order and when I get it) depends largely on the way the order is picked up at:

a. If the customer can always order a SKU in the catalog, the order will be processed based on existing inventories or production program in progress or planned programming; the client will initially be satisfied because it has found what he seeks, and in many cases what we usually want to find; the company will also have a truthful answer invaluable market forecast for marketing purposes. However, it may happen that the order can not be satisfied by a problem in the chain of supplies: is not advisable not to integrate the order on the unit load transport of delivery, wich is generally managed and operated by a logistics operator (which was pre-warned at the time of order with some DRP system), the current trend is that Customer Service will seek to resolve this difficulty informing the customer the possibility of a 
replacement based on the available mix, or processing an incomplete order with some compensation (discount, promotion gift items, etc)

b. If the client can always order just one SKU "validated" ( because there are inventory or current production program), no order can not be served; the point is that the company is losing valuable information on market needs (sometimes there is a module that collects the orders that could not be served by temporary cancellation of the code)

In the industry of non-durable consumer goods (processed foods, groceries, beverages, personal care products, etc) according to the companies, these two modalities are combined:

i. Catalog production (based on sales forecasts, which sales targets overlap) and "push" on the market

\section{Case 7}

PROCTER \& GAMBLE has a successful integrated logistics based on a close monitoring of market trends

ii. Synchronous receiving orders and production, according to "pull" of the market

\section{Case 8}

UNILEVER follows in the footsteps of its permanent competitor, although it is based more on a validated catalog

In the case of manufacturing of durable consumer goods (home appliances, clothing in the niche "premium" etc.) another trend that can reduce inventories, improve the "matching" between production and demand, and process orders more effectively, is the products design that provide the "logistical post-finish" which allows the "customize". This strategy combines a "push" approach to production, with a finish "pull" the product, it is a good compromise to meet demand in metropolitan markets and reduce logistics costs of physical distribution.

\section{$\underline{\text { Case } 9}$}

YAZBEK a leading manufacturer of T-shirts, allows continuous production and subsequent management of product inventory only "white", and color dyes in orders as customers require

\section{Trend 3:}

\section{The batch order processing and limitation to the pulverization of deliveries in e-commerce}

Logistics practices in e-commerce can be discriminated according to two key processes:

- The Order Processing which is always processed in batches (ie not continuously receipt of each order, but when a minimum batch of orders builds up, or opportunities for certain time, or as the order value exceeds a threshold) and it is generally not the delivery territory is distinguished (because in general there is only one Order Processing Center, which can also be a real Distribution Center (DC), and a type of the B2B link with DC of providers catalog; the latter increasingly frequently, and the same logistics operators will make the processes

- The Delivery, which includes transportation and delivery act itself, which is undergoing rapid changes in logistics practices in the metropolitan urban distribution, depending on the level of demand for teleshopping, the characteristics of the urban area and the availability and acceptability (for the consumer) of alternative points of delivery

To sustain the competitiveness of e-commerce with buyers in urban areas, logistics costs in the metropolitan urban physical distribution must not only be controlled but seek alternative methods for delivery involving lower costs.

In so far that e-commerce is becoming more widespread, both specialized logistics operators and the authorities of the municipalities are realizing the importance of limiting the pulverization of deliveries, they begin to generate congestion by increasing delivery vehicles 
on the road network and the extension of the peak period, concentrated in the hours of late afternoon when consumers can receive shipments because they are back from work at home. In this regard, the latest trends in logistics practices focus on engaging the buyer in the production of the physical distribution of what is called the "last mile" of the delivery process, which is where the major costs are concentrated; in particular they are implementing solutions of two types:

i) enable traditional retail outlets to the delivery of the product, which in this case will always have a discount on the price of the catalog (note that the latter may be equal or lower cost than the shelf price)

ii) to equip points-such as terminals affluence of public passenger transport (metro stations, commuter rail, and bus lines headers), public parking with strategic location, service area offices, to particular local malls - an infrastructure of "batteries lockers" with variable legend screens (with the codes of the orders placed there and what locker delivery) and connected to a control software to opening where consumers spend to withdraw their e- order with information submitted in advance by email stating the place near his home where the determined locker containing it is, and the key to opening locker and withdrawal code.

In the Historic Centers and central neighborhoods of some metropolitan areas they are growing online shopping to supermarkets generic products (such as bottled water, cleaning supplies, groceries etc), or where the same supermarkets offer delivery service at no charge to "attendance purchases" in stores, which exceed a minimum amount, municipal authorities are implementing bays in sidewalks for unloading "vans" of the logistics operators who are serving supermarkets, from which they start to be delivered to different apartment buildings; it is important that these operations are being carried out largely at the end of the day, further complicating traffic congestion in the peak period

Caso 10

In the metropolitan area of Mexico City e-business demand is still limited. Essentially the offer is to "be present in the market" (MIXUP), to "give a new opportunity for consumers" (Sanborn's), and in some cases to essentially induce more attendance purchases from "catalog" on the web (LIVERPOOL). Note that Internet sales are not significant for supermarkets; the "super at home" is processed and filled at the nearest shop (SUPERAMA); in this case they have not yet reported "logistical crisis" in the service, as they have been reported for other cities.

\section{Trend 4:}

\section{Development of processes and operations in reverse logistics in order to meet standards and public policies of recycling}

From the perspective of business logistics, reverse logistics is integrated by the following management processes:

i) return products: that were rejected by agents in the marketing channel or by the final consumer as well as "surplus" of inventories by the end of the life cycle (eg by seasonal change, expired due date, etc.)

ii) return products for the re-packaging (product packaging) or change packaging (conditioning a commercial lot): preparation for market packaging (in the vehicle of the main technical mode in the transportation chain) and the management units (for the finished product in the physical distribution chain for the movement and positioning of parts in the manufacturing process, for supplier management on kanban strategies)

iii) recycling of materials: with specific strategies applied to the materials can be recovered for reuse; for examples: the solvents in the extraction processes of edible vegetable oil, the maturation inhibitors gases in containers refrigerators specific for fruits, etc. 
iv) reconditioning of rejected products: through processes of rehabilitation and conditioning, a rejected product can be placed on the market again

v) waste or recycle waste management: such as waste and waste materials of the manufacturing process, packaging (if regulations encourage them back from consumers to points of sale) and packaging (generally consolidated at points of sale to the final consumer ), which often they are sent to third parties for undergoing recycling processes

vi) management of hazardous wastes, they can be sent to recyclers for processing at specific sites to reduce risk (eg, physical, chemical, biological treatment, compaction, incineration, etc.) and then final disposal (landfill, encapsulation confined to ad-hoc facilities, etc.)

vii) management of waste (and recycled waste) for destruction and disposal

viii) handling of recicled materials in order to reduce the use of virgin materials, involving innovations in product design, new strategies of "sourcing" and supplier development and reengineering of logistics procurement

The use in containers, packaging and packaging recycled and recyclable materials is the best strategy for managing household waste; is the way to minimize the use of virgin inputs, and generate less waste must be discarded.

\section{Case 11}

Several manufacturers of non-durable consumer packaged in PET, led by Coca Cola FEMSA, has promoted the creation of ECOCE for the recycling of these containers. The processing plant is still working at less than a third of its capacity. In reverse logistics systems not all outlets have containers available to consumers, no compactors exist in places where higher loading is expected to recycle, and there are no vehicles with the machines that pre-processed containers in the period of transport; however, the most serious is the lack of environmental awareness of consumers: increasing the metropolis becomes a giant outdoor garbage, increasingly in the draining the city are observed more obstructions derived from PET bottles, and is increasingly a potential serious accident by the emission of chlorinated compounds into the atmosphere resulting from the possible burning of PET bottles ... if it happens in the rainy season would lead to a massive lethal acid rain for the few remaining wooded areas in the Valley of Mexico.

\section{Trend 5:}

\section{Introduction of innovations on information technology in logistics}

In logistics of metropolitan urban freight distribution, innovations in information technology (IT) are quickly taken by the impulse of the practices that induce the supermarkets (with sales already represent over $30 \%$ of retail sales in a city).

Among the innovations in IT that will become increasingly banalized in logistics operations of the companies would include:

- RFID for incoming goods and inventory management on shelves

- Transactional software for automatic replenishment and special orders, and for communication of order status

- GPS in vehicles, on-board computer and delivery management

- SKU chip to expedite passage through cash registers

$\underline{\text { Case } 12}$

Just under 5 years that star Walmart's suppliers -BIMBO, FEMSA, SABRITAS, Nestléhave information of each of the point of sales in each of the stores. This allows segmenting the marketing mix as regional market segments, and re-design the supply chain -automatic fulfillments, partial compensation, magement of market emergencies, etc- on each point in the metropolitan geography.

\section{$\underline{\text { Case } 13}$}

Management acknowledgments UPS deliveries are made in the metropolitan area of Mexico City with digitized signature, from the same time that the system was installed 
for all North American operations.

\title{
Trend 6:
}

\section{Technology innovations in vehicles}

The metropolitan urban freight distribution is increasingly demanding the technological innovations in vehicles. The trend shows that the different components for the target vehicle are: van with sliding doors on both sides, low floor, high ceiling to allow the displacement of the operator standing from the cab; engines turbocharged hybrid/electric-diesel; electric vehicles for physical distribution in historic centers and pedestrian areas; innovative chassis materials ("composite") to reduce tare and increase payload capacity; assurance of the "cold chain" for the physical distribution of food products; equipment with GPS and onboard computer.

\begin{abstract}
$\underline{\text { Case } 14}$
The metropolitan physical distribution operations with new Freightliners used by RYDER as logistics operator of JUMEX, the new "van" Mercedes Benz diesel used by FEDEX and DHL, and the innovative italian equipment for cooling in the dedicated fleet for VIP's Restaurants, are emblematic examples of the recent introduction of new technology vehicles in the Metropolitan Area of Mexico City
\end{abstract}

\section{Trend 7:}

\section{Outsourcing operations through logistics operators with dedicated fleet}

Outsourcing in logistics operations through logistics operators is an irreversible trend. Importantly, according to the Mexican Institute of Competitiveness, while in Brazil the level of outsourcing operations reaches over 35\% in Argentina, 30\% in Mexico is not outsource more than $23 \%$.

Based on extensive previous research, based on case studies, it can be stated that:

1) the causes that promote outsourcing operations with logistics operators are: increased turnover in highly competitive environment and need to focus on the "core business", expanding the geographical coverage of the served market and requirement of homogeneity in the level of service, continuous improvement of customer service, reduced product life cycle, the development of new forms of distribution in "point of sales", diversification of the marketing mix and segmentation for different market niches, the extension of the offer with third party products with own brand and conducting telesales and the need for an extensive and micro physical distribution

2 ) the pretexts underlying corporate decision to outsource are: avoid high investment peripheral to the "core business", transparent logistics costs gain economies of competition, have sophisticated tools (WHMS, RFID, etc) to manage the logistics processes, facilitate access to technological innovations in logistics to gain competitiveness, and use logistics as extreme strategy to add value

3) to implement strategies for outsourcing are varied, and include options such as: externalize internal logistics department, to establish contract with third-party logistics services, establish strategic alliances with logistics operators "3PL", participate in projects of logistics benchmarking with external consultants, and purchasing specialized consulting services as "4PL"

4) the results that companies have obtained after outsourcing logistics operations are: improvement in the profitability of assets available, improved management of the logistics system, allows the targeting of resources on the "core business", exploits the "know how" of specialists, improves productivity, clarifies logistics costs, reduces the risk in the selection of locations of logistics supports

The leaders companies in the production of consumer goods increasingly outsource their logistics operations, and trends indicate that seeks to develop specialized logistics operators 
(OL) with partially or full dedicated Distribution Centers, fleet vehicles dedicated to serving the load "customized" (temperature and controlled atmosphere, charging unit that can process orders for pre-sale physical distribution, autosale physical \& commercial distribution, etc.), and development of Urban Logistics Microplatafforms for cross-docking and redistribution in smaller and adapted vehicles

\section{Case 15}

RYDER has integrated, by rent, into a fleet dedicated to distribution metropolitan for JUMEX, some vehicles that had been purchased by JUMEX before corporate decision to outsource these operations. With successful dedicated services to NESTLE in the metropolitan area of Mexico City, TRANSPORTE Y DISTRIBUCION, recently have faced the challenge of distribution in major cities.

\section{Trend 8:}

\section{Preference for the location of corporate own logistics support and/or operation with} dedicated logistics operators in logistics centers

One of the global trends of interest for the design of public policies for managing the flow of vehicles transport demand metropolitan cargo is the corporate preference for establishing or search logistical platforms; ie: prefer location of own logistics infrastructure or their logistics operators, for the urban and metropolitan physical distribution, in Logistics Centers or Logistics Park.

While all "breakdown", either the "charging unit" or the "traction", implies costs, operation based on Logistics Centers enables companies to manage: i) restrictions arising from municipal regulations, and ii) focus the urban physical distribution avoiding the costs of deliveries with multiple stops.

- A logistics architecture with Logistics Centers provides companies to manage extra-metropolitan flows that are made with large cargo units (trailers, "fulles", "dollies", etc.) through "cross-docking" and routes that serve a number of points of sale with the centralized deliveries

\section{Case 16}

EXEL Logistics operation, currently a subsidiary of DHL, are preferring facilities in San Martin Obispo in the north of the Metropolitan Area of Mexico. Another subsidiary of DHL, Kuehne + Nagel has installed its operations dedicated inventory management and order processing for pharmaceutical laboratories leaders in the FINSA Industrial Park near Xochimilco, a location south of the metropolis, well suited to transfer the store finished product production plant in Colonia del Valle.

- Using Urban Logistics Micro-Platform for delivery in historic centers and conflicting urban areas allows efficient and profitable operation (by the size of the electric van) they can reach a reasonable and more secure and reliable delivery

\section{Case 17}

For the physical distribution of high turnover consumer products from Coca Cola FEMSA, and SABRITAS (Fritolay) are used incorporated electric vehicles and Urban Logistics Micro-plattaforms (UlmP).

- On the other hand, private real estate developers in the logistics sector, are consolidating a wide and diversified range of customized infrastructure and logistics buildings offered for rent, in premium locations: new logistics parks in San Martin Obispo (state of Mexico), in recycled industrial parks like Tepeji del Río (state of Hidalgo), new clusters as Huehuetoca (states of Mexico and Hidalgo), the Mexiquense Circuit (state of Mexico), and developing new projects on the new Arco Norte at Jilotepec (state of Mexico) and San Martin Texmelucan (state of Puebla).

Case 18:

LIVERPOOL opened a new distribution center (DCs) for the "big ticket" in Huehuetoca, and a few months later, in neighborhood, and on the railways of Kansas City Southern and Ferromex, MABE opened its new distribution center. MICHELIN opened in the 
most important Distribution Centers in Americas in San Martin Obispo. All leading supermarket chains recently opened new Distribution Centers: WALMART in San Martin Obispo, CHEDRAUI on the new Circuit Mexiquense, and COSTCO in Tepeji del Río.

\section{CONCLUSION}

It is desirable to promote in Latin American metropolitan areas Observatories of Best Logistics Practices on Urban Freight, with the participation of companies and academic centers of applied research in logistics (Antún, JP, 2015)

\section{REFERENCES}

ANTÚN, JP; LOZANO, A; HERNÁNDEZ, R; ALARCÓN, R et al (2007) "Proyecto de desarrollo de Soportes Logísticos de Plataforma (SLP) para la Zona Metropolitana del Valle de México (ZMVM)”, Tarea 5 en Lozano, A et al (2007) Programa Metropolitano de Transporte de Carga y Medio Ambiente para el Valle de México (PMTCMA-VM), Instituto de Ingeniería (UNAM) - Fideicomiso Ambiental de la Comisión Ambiental Metropolitana, México DF.

ANTÚN, JP; LOZANO, A; MAGALLANES, R; ALARCÓN, R; GRANADOS, F (2009) Estrategias para el ordenamiento territorial logístico competitivo de la Región Centro, Instituto de Ingeniería (UNAM) Programa de Competitividad en Logística y Centrales de Abasto (PROLOGYCA), Secretaría de Economía, Gobierno Federal, Fideicomiso para el Desarrollo de la Región Centro País (FIDCENTRO), México DF.

ANTÚN JP, ALARCÓN R (2014) Estrategias para el mejoramiento de la logística de distribución de mercancías en el Núcleo de Mercados de La Merced, Instituto de Ingeniería (UNAM)- Secretaría de Desarrollo Económico (SEDECO) del Gobierno de la Ciudad de México, México DF.

ANTÚN JP (2015) Benchmarking de procesos logísticos en distribución urbana de mercancías, Instituto de Ingeniería (UNAM) - Asociación Nacional de Transporte Privado (ANTP), México DF. 